\title{
LHCP four patches stack triangular truncated antenna using corporate feed microstrip-line for CP-SAR sensor
}

\author{
Muhammad Fauzan Edy Purnomoํ, Vita Kusumasari², Rudy Yuwono ${ }^{3}$, Rahmadwati ${ }^{4}$, \\ Rakhmad Romadhoni ${ }^{5}$, Azizurrahman Rafli ${ }^{6}$, Yuyu Wahyu ${ }^{7}$, Akio Kitagawa ${ }^{8}$ \\ 1,3,4,5,6Electrical Department, Faculty of Engineering, Brawijaya University, Malang, Indonesia \\ ${ }^{2}$ Mathematics Department, Faculty of Mathematics and Natural Sciences, Universitas Negeri Malang, Malang, Indonesia \\ ${ }^{7}$ Research Center for Electronics and Telecommunications, Indonesian Institute of Sciences (LIPI), Bandung, Indonesia \\ ${ }^{8}$ Electrical Engineering and Computer Science, Kanazawa University, Ishikawa, Japan
}

\begin{tabular}{|c|c|}
\hline Article Info & ABSTRACT \\
\hline Article history: & In this paper, we acquire the configuration of the left-hand circular \\
\hline Received Dec 27, 2020 & $\begin{array}{l}\text { polarization (LHCP) array four patches stack triangular truncated microstrip } \\
\text { antenna. This construction use the basic corporate feed microstrip-line with }\end{array}$ \\
\hline Revised Mar 15, 2021 & modified lossless T-junction power divider on radiating patch for circularly \\
\hline Accepted Apr 11, 2021 & $\begin{array}{l}\text { polarized-synthetic aperture radar (CP-SAR) sensor embedded on unmanned } \\
\text { aerial vehicle (UAV) with compact, small, and simple configuration. The }\end{array}$ \\
\hline Keywords: & $\begin{array}{l}\text { design of circular polarization }(\mathrm{CP}) \text { is realized by truncating the whole three } \\
\text { tips and adjusting the parameters of antenna at the target frequency, }\end{array}$ \\
\hline Corporate feed microstrip-line & $f=5.2 \mathrm{GHz}$. The results of characteristic performance and $S$-parameter for the \\
\hline CP-SAR & LHCP array four patches stack antenna at the target frequency show \\
\hline Four patches stack & successively about 9.14 abic or gain, $2.89 \mathrm{CB}$ or axial ratio $(A r)$, and \\
\hline LHCP & $3 \mathrm{~dB}-\mathrm{Ar}$ bandwidth of this antenna are around $410 \mathrm{MHz}(7.89 \%)$ and \\
\hline Triangular truncated & $100 \mathrm{MHz}(1.92 \%)$, respectively. \\
\hline
\end{tabular}

This is an open access article under the $\underline{C C B Y-S A}$ license.

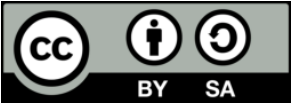

\section{Corresponding Author:}

Muhammad Fauzan Edy Purnomo Department of Electrical Engineering Faculty of Engineering, Brawijaya University MT. Haryono 167, Malang 65145, Indonesia Email: mfauzanep@ub.ac.id

\section{INTRODUCTION}

Radar is an electronic device that utilizes a lot special technology, including signal processing, data processing, waveform design, detection, parameter estimation, and antenna propagation. The radar antenna transmits pulses of microwaves that bounce off any object in their path. The object returns a portion of the wave to the receiver which is in line of sight with the target [1].

Radar is a remote sensing system, which is widely used for monitoring, tracking and imaging applications. Remote sensing system use the side-looking images which are divided into two types: i) Real aperture radar (RAR), ii) Synthetic aperture radar (SAR). Remote sensing has been implemented for defense, disaster mitigation, earth and atmosphere observations, and mapping [2]-[4].

This paper presents the development of the left-hand circular polarization (LHCP) array four patches stack triangular truncated microstrip antenna. The study involves the development of the four patches as basic construction for CP-SAR sensor. This construction uses the double-stacked substrate with low dielectric constant, modified triangular truncated radiating patch shape using microstrip-line for multiresonant frequency, and triangular truncated parasitic patch for $\mathrm{CP}-\mathrm{SAR}$ sensor embedded on unmanned 
aerial vehicle (UAV) with compact, small, and simple configuration that fundamentally construct to mold a substantial planar array. This design is modified from previous research about the antenna without patch stack and the use of the proximity feeding [5]. The new antenna design has ability to work in higher frequency and to achieve the wider bandwidth of impedance and axial ratio. The design of power divider network is often limited by the restrictions imposed by radiating patches dimensions. The feeding network is a multi-port power divider circuit which is an important element in the design of corporate feed beamforming network configuration. The power is distributed to radiating patches through the multi-port power divider. This is also a microwave device that is useful for phased-array antennas, mixers, and active devices. This modified antenna design is fed by $1: n$ ( $n$ is a number of patches) power divider network involving Tjunctions called corporate feeding-line. T-junctions are compensated by adjusting the length of the three microstrip-lines where the length of two or three of them is about $\lambda / 4$ for matching impedance $50 \Omega$ [5]-[8].

By incorporating proper line extensions toward patches and adjacent patches in the left-right sides on the opposite direction of $180^{\circ}$ and also add more patches, the beam direction can be controlled. For a symmetric corporate feeding-line network, the number of radiating patches is $2^{m}$ ( $m$ is an integer indicating the number of T-junctions toward patches for one patch, two and four patches, while for eight patches, $m$ is an integer denoting the number of T-junctions which are not through patches, and for sixteen, thirty-two, sixty-four, one hundred and twenty-eight, etc. patches, $\mathrm{m}$ is an integer exhibiting the number of $\mathrm{T}$-junctions which are not through patches and input port divided by two and added with one). Furthermore, radiating patches are matched by the corporate feeding-line through appropriate dimension of coupling structures or by using quarter-wave transformers that one of them is to make the distance between the tip of corporate feeding-line on radiating patch and null potential $(O), l f$, is $4.41 \mathrm{~mm}$. To obtain the array antenna operating the $\mathrm{TM}_{21}$ circular polarization (CP), we use the following rules [9]: i) The radiating patches with corporate feed microstrip-line that use the perturbation segment on the radiating and parasitic patches. In this case, the substrate thickness of radiating patches with corporate feed microstrip-line $(h l)$ and parasitic patches $(h 2)$ are the same with the value is $1.6 \mathrm{~mm}$; ii) To create the stable radiation patterns which are slightly symmetric at the boresight beam, the element spacing of radiating patches is $\lambda / 2$. Furthermore, the tips of corporate feed microstrip-line which have the same parameter sizes spread the current within radiating and parasitic patches. To establish CP, we require the proper setting size between the tips of corporate feed microstrip-line and the perturbation segment on the radiating and parasitic patches. Owing to the both of them strongly affected with a high degree of sensitivity, they yield two orthogonal resonant modes of equal amplitudes and $90^{\circ}$ phase difference; iii) In order to preserve the symmetric beam and to keep the low CP, wider ARBW, and the higher gain, this antenna using triangular truncated parasitic patches with area around remaining part is covered with substrate. In this paper, we describe the corporate feeding-line of five ports for four patches of LHCP array antennas that close lossless, reciprocal $(-6 \mathrm{~dB})$ and matched load. The results obtained from the study reveal $S$-parameter, frequency characteristic, input impedance, radiation pattern, and antenna efficiency of this modified antenna.

\section{RESEARCH METHOD}

In this investigation, we conduct and discuss numerical simulation result related to the microstrip antenna with research method and construction described in Figure 1 and Figure 2 (in appendix). In particular, the analysis focuses on the study of triangular truncated array $2 \times 2$ patches antenna for LHCP. In this case, the array antenna uses four patches as a transmitter, $T x$, and a receiver, $R x$ [10], [11]. Table 1 shows the specification for the $C$-Band CP-SAR of UAV antenna [12]. The method of moments (MoM) is chosen in the numerical analysis for fast calculation. This method discretizes the integral into a matrix equation. This discretization can be considered as dividing the surface of antenna into small mesh [4]. To realize this method, we use computer simulation technology (CST) version 2016 from corporate company CST STUDIO SUITE [13]. The numerical simulation of the triangular truncated array antenna are shown in section 3, especially at the target frequency, $f=5.2 \mathrm{GHz}$ where this antenna as basic configuration embedded on UAV for the application of CP-SAR sensor both $T x$ and $R x$. Each antenna can generate wave that yields a CP. The technique to achieve $\mathrm{CP}$ can be easily obtained i.e. by proper adjusting of the parameters, determining locus feed, and constructing feed [14], [15].

To investigate the low power of the LHCP array four patches stack triangular truncated microstrip antenna, the antenna is constructed the mold of substantial planar array using microstrip-line that is fed directly to radiating patches and impacts on parasitic patches to yield the $\mathrm{CP}$ with wider bandwidth than other antennas operated in LP [19]-[21] and CP [22], [23]. It is because the right pattern of basic construction determines the superiority of array antenna design using patches stack and corporate feed microstrip-line [15], [24]-[26]. Although the corporate feeding-line design has been developed [5], [14], [27], the design was for the antenna bandwidth (IBW and ARBW) smaller than this novel antenna. In this paper, nippon pillar 
packing (npc) H220A is chosen as the antenna substrate. It has a conventional substrate with dielectric constant $\left(\varepsilon_{r}\right)$, and loss tangent $(\delta)$ are 2.17 and 0.0005 , respectively. Moreover, the total substrate thickness of LHCP antenna is $3.2 \mathrm{~mm}$. Also, the design of LHCP four patches array antenna fed by corporate feed microstrip-line having low power and the antenna view on the $35^{\circ}$ angle side for CP-SAR application are discussed.

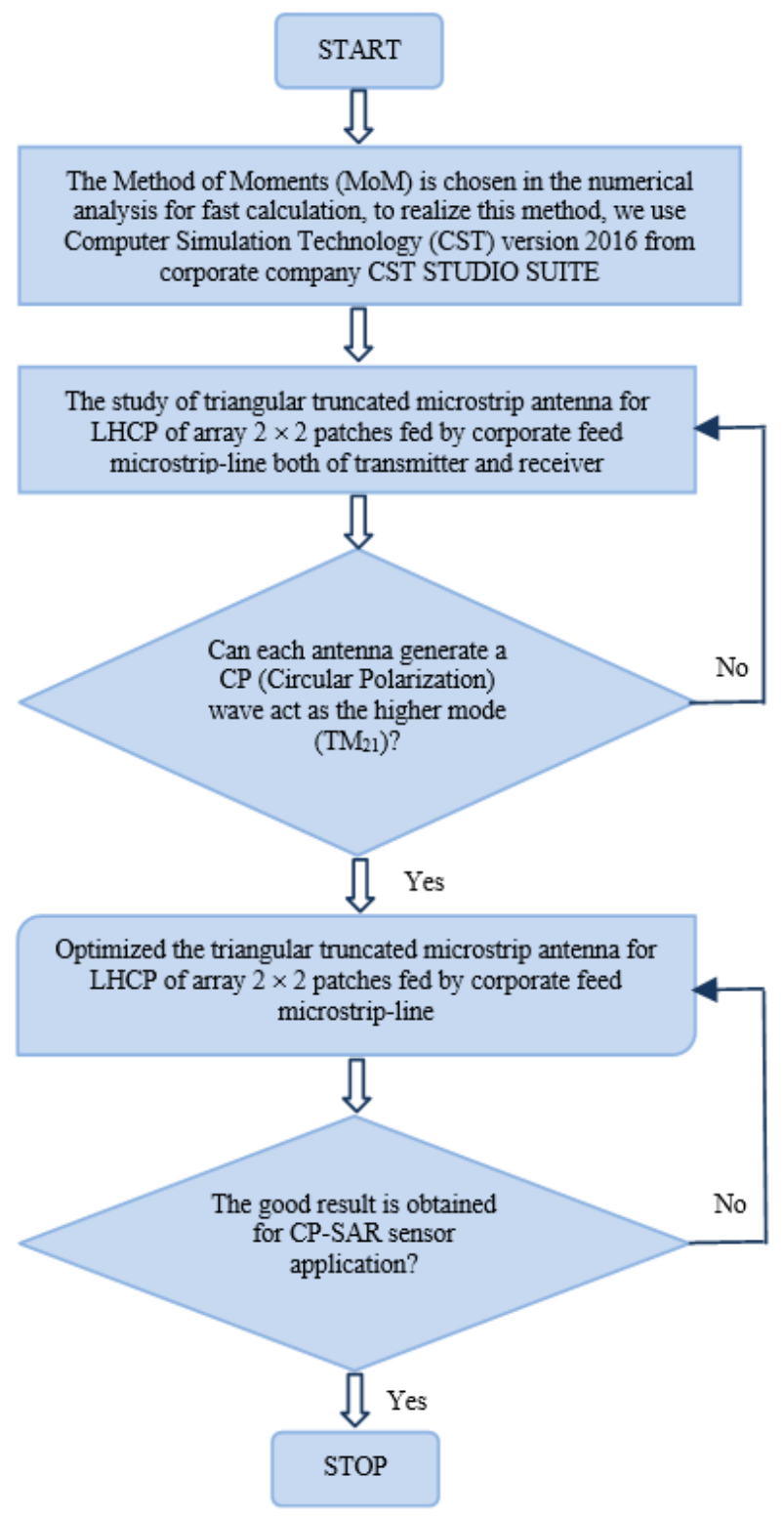

Figure 1. The flowchart of research method of array four patches stack LHCP antenna [16]-[18]

Table 1. Technical specification of UAV system

\begin{tabular}{cll}
\hline No & \multicolumn{1}{c}{ Antenna Parameters } & \multicolumn{1}{c}{ Specification for UAV } \\
\hline 1. & Target Frequency (Center) $(\mathrm{GHz})$ & $C$-band: $5.0-5.5 \mathrm{GHz}$ \\
2. & Pulse Band Wide $(\mathrm{MHz})$ & $10-233.31$ \\
3. & Axial Ratio $(\mathrm{dB})$ & $\leq 3$ \\
4. & Antenna Efficiency $(\%)$ & $>80$ \\
5. & Gain Antenna (dBic) & $9.6-36.6$ \\
6. & Azimuth Beamwidth $\left(^{\circ}\right)$ & $\geq 1.08$ \\
7. & Elevation Beamwidth $\left({ }^{\circ}\right)$ & $\geq 2.16$ \\
8. & Antenna Size $(\mathrm{m})$ & $0.6 \times 0.5$ \\
9. & Polarization $(T x / R x)$ & $\mathrm{RHCP}+\mathrm{LHCP}$ \\
\hline
\end{tabular}




\section{RESULTS AND DISCUSSION}

Figure 3 shows that the values of gain and axial ratio $(A r)$ for simulation of the LHCP array four patches stack triangular truncated microstrip antenna in the direction of $\theta=35^{\circ}$ at the target frequency, $f=5.2 \mathrm{GHz}$, are about $9.74 \mathrm{dBic}$ and $2.89 \mathrm{~dB}$, respectively. In addition, the $3 \mathrm{~dB}-A r$ bandwidth is roughly equal $100 \mathrm{MHz}(1.92 \%)$. Figures 4 and 5 shows the relationship between the reflection of coefficient $\left(S_{11}\right)$ or VSWR and the frequency for the simulation $T x / R x$ array four patches stack triangular truncated microstrip antenna. Moreover, the value of $S_{11}$ or VSWR at the target frequency is $-10.91 \mathrm{~dB}$ or 1.813 , respectively. While the $S_{11}$ or VSWR bandwidth is around $410 \mathrm{MHz}(7.89 \%)$. Figure 6 depicts the input impedance characteristic of the LHCP array four patches stack triangular truncated microstrip antenna for the real part and the reactance part of simulation at the target frequency that are successively $50.29 \Omega$ and $-14.79 \Omega$. These results are relative close to $50 \Omega$ and $0 \Omega$, so the reactance looks capacitive. In the feed network, the length from input port to output ports must be fixed at $l \times \lambda / 4(l=1,3$, and 5) to achieve the optimal current intensity [27]. In this work, we use $l=9$ or the distance between input port to output ports is $138.5424 \mathrm{~mm}$.

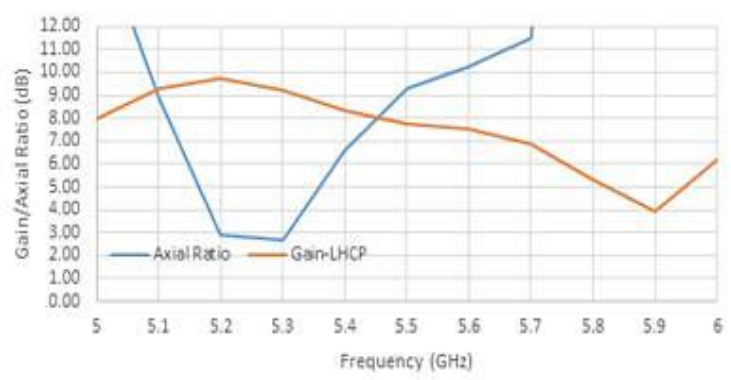

Figure 3. Frequency characteristic of $2 \times 2 \mathrm{LHCP}$ antenna

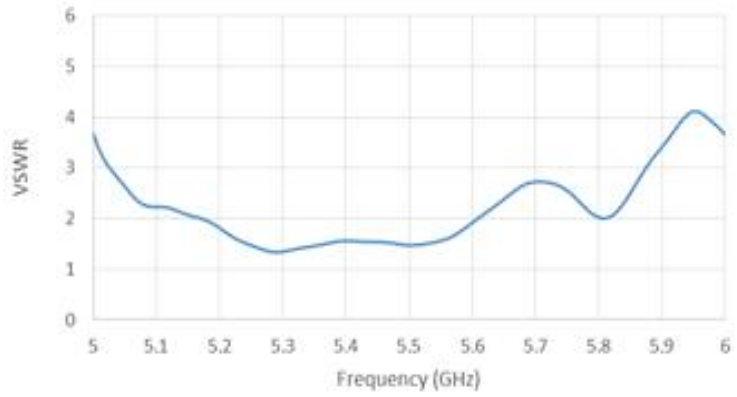

Figure 5. VSWR of $2 \times 2$ LHCP antenna

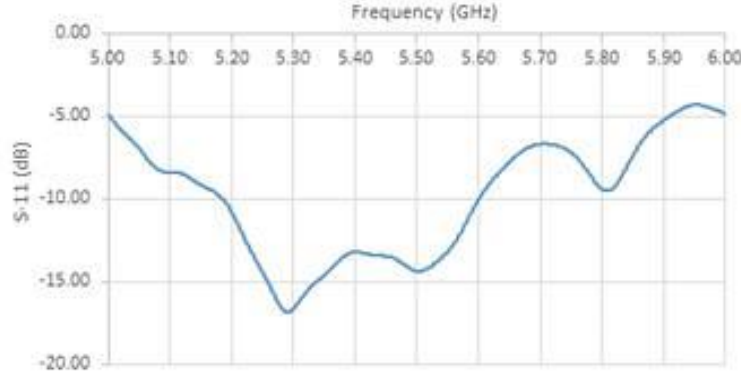

Figure 4. $S$-parameter of $2 \times 2$ LHCP antenna

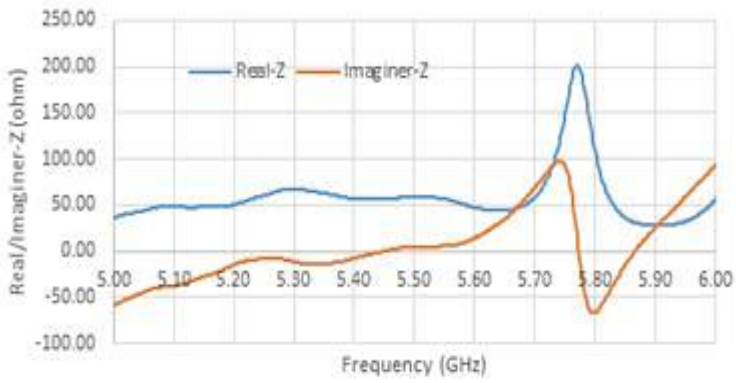

Figure 6. Input impedance of $2 \times 2$ LHCP antenna

Figures 7 and 8 depict the relationship between gain- $A r$ and $\theta$ (Theta)-angle produced from the LHCP array four patches stack triangular truncated microstrip antenna as azimuth $(A z / \phi)$ direction (positive- $\theta$ for direction to $\phi=0^{\circ}$ or $\phi=90^{\circ}$ and negative $\theta$ for direction to $\phi=180^{\circ}$ or $\phi=270^{\circ}$ ) of CP-SAR at $f=5.2 \mathrm{GHz}$. At $\theta=35^{\circ}$, the average values of maximum gain and $A r$ of this antenna are about $9.74 \mathrm{dBic}$ and $2.89 \mathrm{~dB}$, respectively. Furthermore, the values of $3 \mathrm{~dB}-A r$ beamwidth are $75^{\circ}$ from $-100^{\circ}$ to $-25^{\circ}$ (direction to $\phi=180^{\circ}$ and $\phi=270^{\circ}$ or negative- $\theta$ ) and around $68^{\circ}$ from $2^{\circ}$ to $70^{\circ}$ (direction to $\phi=0^{\circ}$ and $\phi=90^{\circ}$ or positive- $\theta$ ). All of these values satisfy the targeted elevation beamwidth of $\geq 2.16^{\circ}$ at Table 1 for better resolution of CP-SAR.

Figures 9 and 10 describe the $\phi$ (Phi)-plane in the area of $\theta=35^{\circ}$ for LHCP at frequency $5.2 \mathrm{GHz}$. The values of maximum gain and minimum $\mathrm{Ar}$ on this plane are $9.744 \mathrm{dBic}$ on $\phi=0^{\circ}$ and $1.3 \mathrm{~dB}$ on $\phi=145^{\circ}$. The major values of $3 \mathrm{~dB}-A r$ beamwidth on $\phi$ (Phi)-plane, direction to $\phi=0^{\circ}$ are about $63^{\circ}$ from $\phi=317^{\circ}$ or $-43^{\circ}$ to $\phi=20^{\circ}$ and around $60^{\circ}$ from $\phi=137^{\circ}$ to $\phi=197^{\circ}$ or $-163^{\circ}$. While for the $\phi$ (Phi)-plane, direction to $\phi=90^{\circ}$ are roughly $65^{\circ}$ from $\phi=45^{\circ}$ to $\phi=110^{\circ}$ and approximately $63^{\circ}$ from $\phi=227^{\circ}$ or $-133^{\circ}$ to $\phi=290^{\circ}$ or $-70^{\circ}$. These results exhibit that the targeted azimuth beamwidth $\geq 1.08^{\circ}$ can occur for the resolution of $\mathrm{CP}-$ SAR UAV. Figure 11 shows the antenna efficiency about $89.23 \%$ for the LHCP array four patches stack 
triangular truncated microstrip antenna on a target frequency of $5.2 \mathrm{GHz}$. This result obtain the resolution of CP-SAR of the targeted antenna efficiency of $80 \%$.

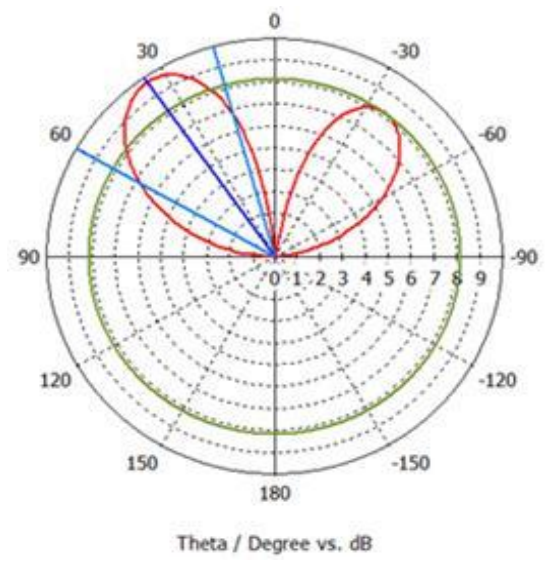

(a)

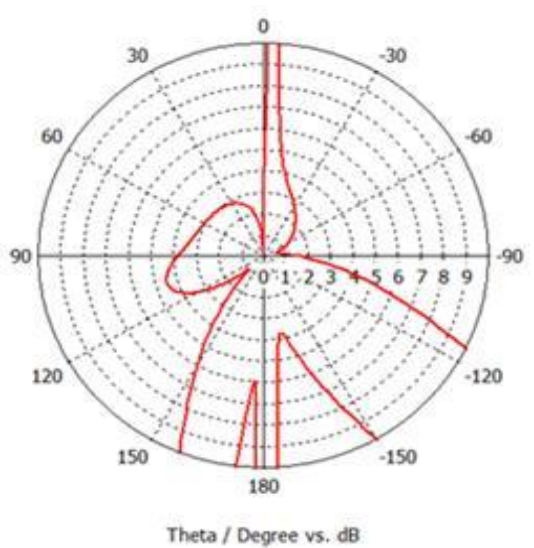

(b)

Figure 7. Farfield; (a) gain, (b) axial ratio of $2 \times 2 \mathrm{LHCP}$ antenna, $\phi=0^{\circ}, f=5.2 \mathrm{GHz}$

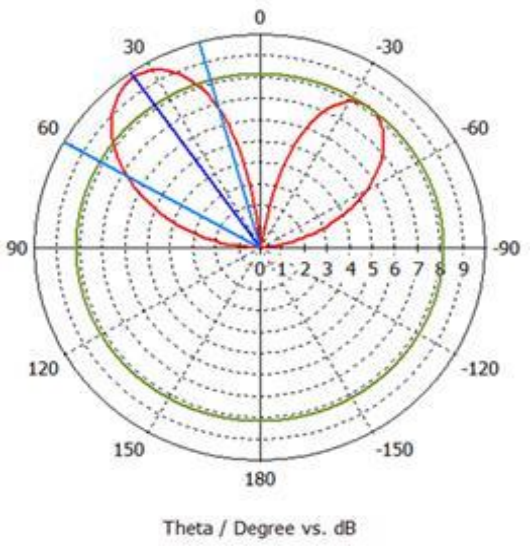

(a)

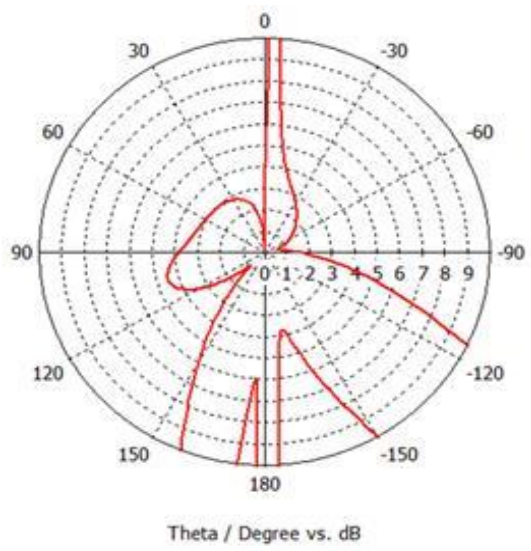

(b)

Figure 8. Farfield; (a) gain, (b) axial ratio of $2 \times 2 \mathrm{LHCP}$ antenna, $\phi=90^{\circ}, f=5.2 \mathrm{GHz}$

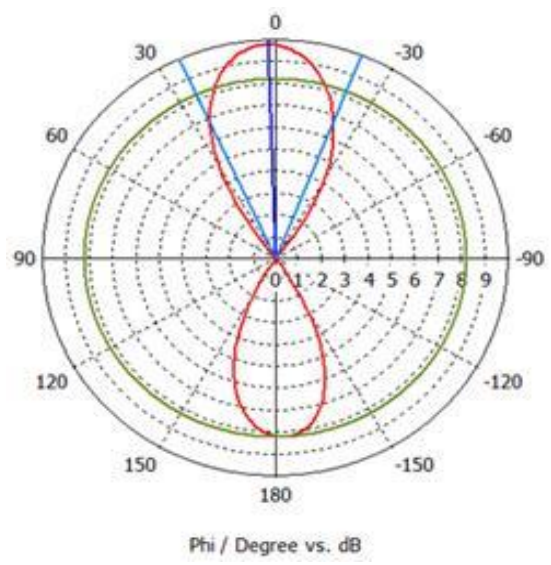

(a)

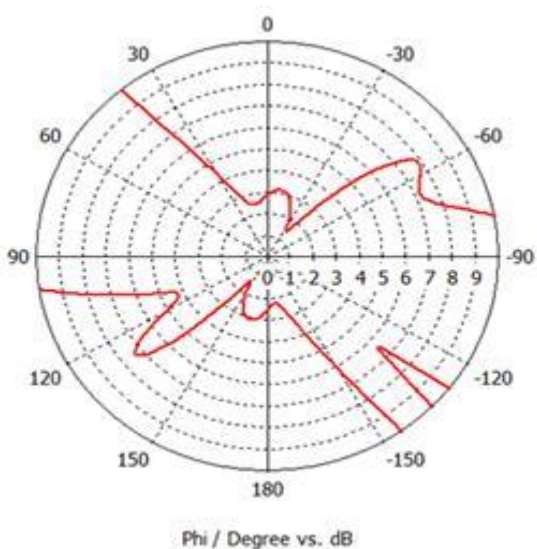

(b)

Figure 9. Farfield; (a) gain, (b) axial ratio of $2 \times 2 \mathrm{LHCP}$ antenna, $\theta=35^{\circ}, \phi=0^{\circ}, f=5.2 \mathrm{GHz}$ 


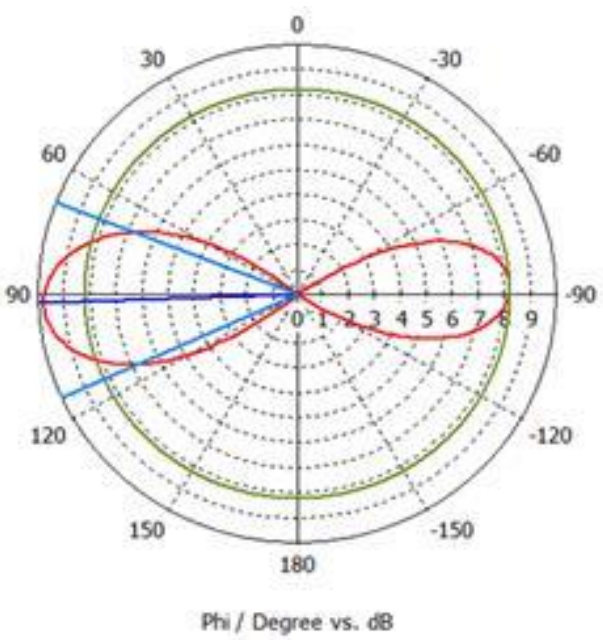

(a)

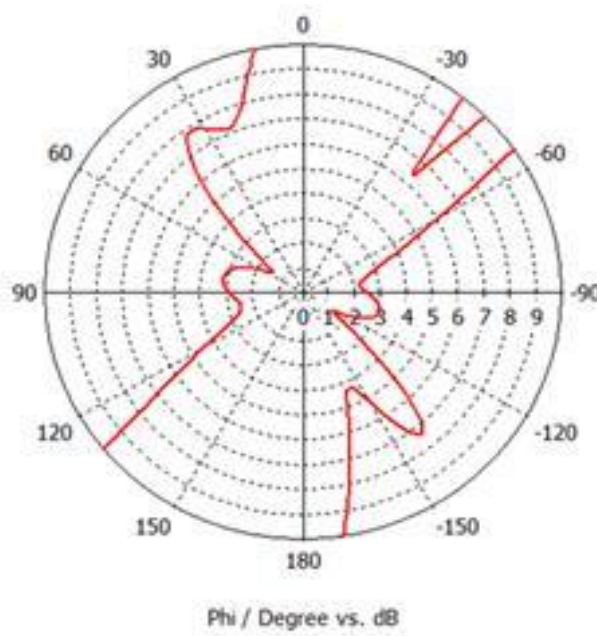

(b)

Figure 10. Farfield; (a) gain, (b) axial ratio of $2 \times 2 \mathrm{LHCP}$ antenna, $\theta=35^{\circ}, \phi=90^{\circ}, f=5.2 \mathrm{GHz}$

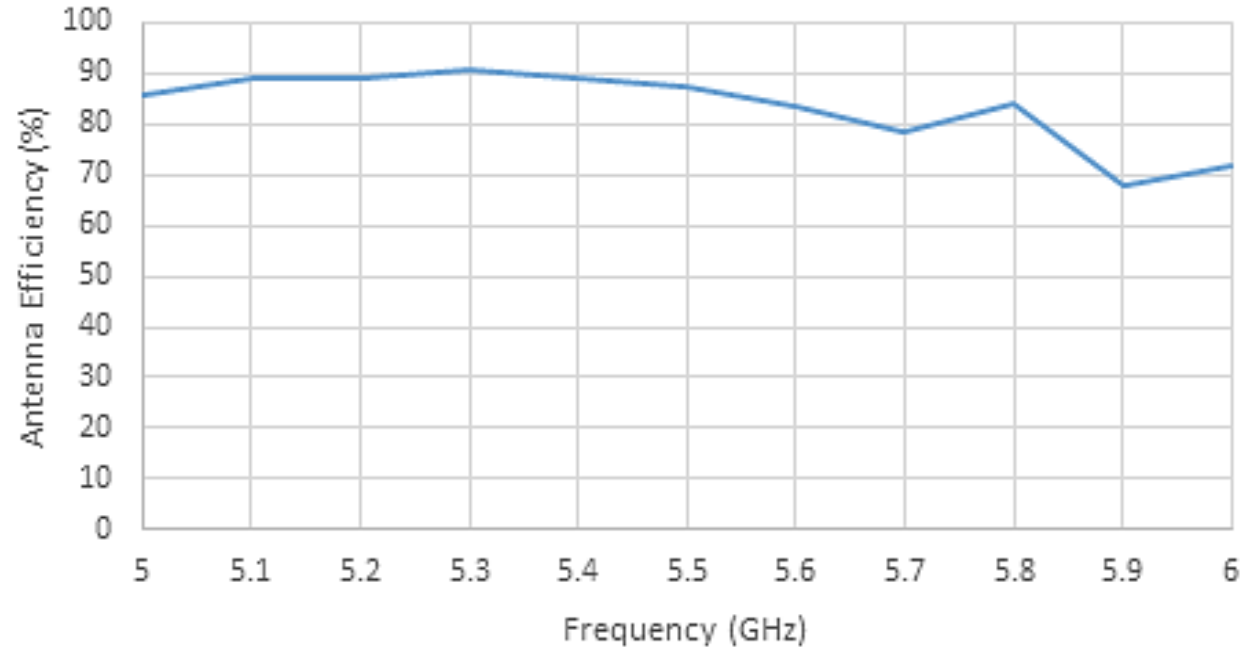

Figure 11. Antenna efficiency of $2 \times 2$ LHCP antenna

\section{CONCLUSION}

In an effort to meet the configuration for CP-SAR that is affixed to the UAV body with compact, small and simple, the LHCP array four patches stack triangular truncated microstrip antenna has been studied. Performance results, such as characteristic frequencies, $S$-parameters, input impedances, radiation patterns, and efficiency are as follows: i) The gain and axial ratio (Ar) values for this antenna simulation in the direction $\theta=35^{\circ}$ at target frequency of $5.2 \mathrm{GHz}$, were respectively around $9.74 \mathrm{dBic}$ and $2.89 \mathrm{~dB}$; ii) $3 \mathrm{~dB}-\mathrm{Ar}$ bandwidth of $100 \mathrm{MHz}(1.92 \%)$ was relatively wider than working on the $C$-band frequency; iii) The value of $S_{11}$ or VSWR at the target frequency was $-10.91 \mathrm{~dB}$ or 1.813 and its bandwidth value was around $410 \mathrm{MHz}(7.89 \%)$; iv) Input impedance of the real part of this antenna from simulation at resonance frequency, $f=5.2 \mathrm{GHz}$ was $50.29 \Omega$ relatively close to $50 \Omega$. While the reactance portion of this antenna was $-14.79 \Omega$, it looked capacitive and approached $0 \Omega$; v) The maximum gain and the minimum $A r$ values of this antenna in the gain-axial ratio function to the $\theta$ (Theta)-angle were around $8,14 \mathrm{dBic}$ and $2,46 \mathrm{~dB}$ at $\theta=-35^{\circ}$ and around $9.74 \mathrm{dBic}$ and $2,89 \mathrm{~dB}$ at $\theta=35^{\circ}$; vi) The maximum gain and minimum $A r$ values in the relation function of gain-axial ratio to $\phi$-angle were about $9.744 \mathrm{dBic}$ at $\phi=0^{\circ}$ and $1.3 \mathrm{~dB}$ at $\phi=145^{\circ}$; vii) The antenna efficiency value of this antenna was around $89.23 \%$ at a target frequency of $5.2 \mathrm{GHz}$ which has exceeded the target set by more than $80 \%$. 


\section{APPENDIX}

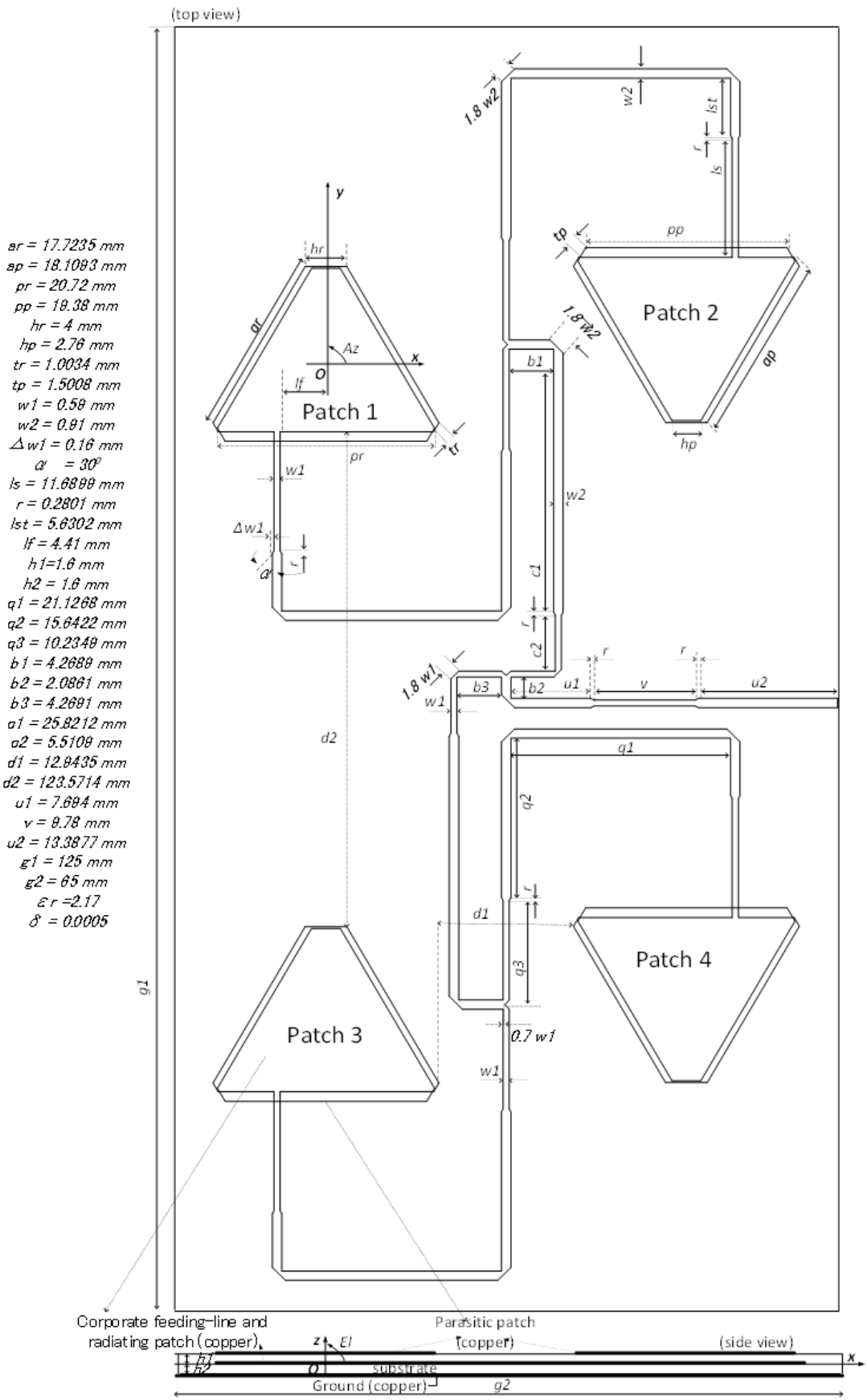

Figure 2. The construction of array four patches stack LHCP antenna

\section{ACKNOWLEDGEMENTS}

The authors would like to express their gratitude to BPPM of the Faculty of Engineering, Brawijaya University who has awarded the assistant professor's doctoral grant for the funding of this publication. Great thank to the Power System Engineering and Energy Management Research Group (PSeemRG), Electrical Engineering Department, Faculty of Engineering, Brawijaya University for the support that the first author is a member of this research group. Also, special thanks to the Microelectronic Research Laboratory (MeRL), Electrical Engineering and Computer Science, Graduate School of Natural Science and Technology, Kanazawa University, Japan for the support of facilities to collect the data in this research. 


\section{REFERENCES}

[1] M. Y. Bendimerad, N. Djedoui, D. Boukern, and F. T. Bendimerad, "Radar Prototype System for Target Detection and Tracking," The First International Conference on Networking Telecommunications, Biomedical Engineering and Applicatons, Algeria, Nov. 2019.

[2] F. S. Marzano, S. Marchiotto, C. Textor, and D. J. Schneider, "Model Based Weather Radar Remote Sensing of Explosive Volcanic Ash Eruption," IEEE Transactions On Geoscience and Remote Sensing, vol. 48, no. 10, pp. 3591-3607, Oct. 2010.

[3] F. Tessitore, "Aerial Surveillance and Airborne Remote Sensing Techniques in Guardia di Finanza: An Operational Experience," International Carnahan Conference on Security Technology (ICCST), 2014, pp. 1-6.

[4] Y. Zhou, S. Wang, W. Zhou, and P. Zhang, "Applications of CBERS-2 Image Data in Flood Disaster Remote Sensing Monitoring," International Geoscience and Remote Sensing Symposium (IGARSS), 2004, vol. 7, pp. 4696-4699.

[5] M. F. E. Purnomo and A. Kitagawa, "Triangular Microstrip Antenna for Circularly-Polarized Synthetic Aperture Radar Sensor Application,” Indonesian Journal of Electrical Engineering and Computer Science, vol. 12, no. 1, pp. 310-318, Oct. 2018, doi: 10.11591/ijeecs.v12.i1.pp310-318.

[6] J. M. Parenreng and A. Kitagawa, "Resource Optimization Techniques and Security Levels for Wireless Sensor Networks Based on the ARSy Framework," Sensors, vol. 18, no. 1594, pp. 1-15, 2018.

[7] P. D. P. Adi and A. Kitagawa, "ZigBee Radio Frequency (RF) Performance on Raspberry Pi 3 for Internet of Things (IoT) Based Blood Pressure Sensors Monitoring," (IJACSA) International Journal of Advanced Computer Science and Applications, vol. 10, no. 5, pp. 18-27, 2019.

[8] K. C. Gupta, R. Garg, and I. J. Bahl, "Microstrip Lines and Slotlines," Second Edition, Artech House, Inc., 1996.

[9] B. Du and E. K. N. Yung, "A Single-feed TM 21 Mode Circular Patch Antenna with Circular Polarization," Microwave and Optical Technology Letters, vol. 33, pp. 154-155, May 2002.

[10] J. T. S. Sumantyo, K. Ito, and M. Takahashi, "Dual-Band Circularly Polarized Equilateral Triangular-Patch Array Antenna for Mobile Satellite Communications," IEEE Transactions on Antennas and Propagation, vol. 53, no.11, pp. 3477-3485, Nov. 2005.

[11] M. F. E. Purnomo, S. Pramono, M. A. Pamungkas, and T. Taufik, "Study of The Effect of Air-Gap on Array Microstrip Antenna Performances for Mobile Satellite Communications," ARPN Journal of Engineering and Applied Sciences, vol. 10, no. 20, pp. 9808-9815, Nov. 2015.

[12] M. F. E. Purnomo and A. Kitagawa, "Analysis Performance of Triangle Microstrip Antenna for Basic Construction of Circularly Polarized-Synthetic Aperture Radar Application,” Jurnal TEKNOLOGI, vol. 80, no. 2, pp. 93-104, Mar. 2018, doi: 10.11113/jt.v80.11119.

[13] CST STUDIO SUITE 2016, "Microwave - Radio Frequency - Optical," Copyright (C) 1998 - 2016 CST AG, Release version 2016, Nov. 2016.

[14] M. Baharuddin, V. Wissan, J. T. S. Sumantyo, and H. Kuze, "Equilateral Triangular Microstrip Antenna for Circularly-Polarized Synthetic Aperture Radar," Progress In Electromagnetics Research C., vol. 8, pp. 107-120, 2009.

[15] C. L. Tang, J. H. Lu, and K. L. Wong, "Circularly Polarized Equilateral-Triangular Microstrip Antenna with Truncated Tip,” Electron. Letter, vol. 34, no. 13, pp. 1227-1228. Jun. 1998

[16] C. E. Santosa, J. T. S. Sumantyo, and K. Urata, "Development of a Low Profile Wide-Bandwidth Circularly Polarized Microstrip Antenna for C- Band Airborne CP-SAR Sensor," Progress In Electromagnetics Research, vol. 81, pp. 77-88, 2018

[17] C. E. Santosa, J. T. S. Sumantyo, and M. Y. Chua, "Subarray Design for $C$-Band Circularly-Polarized Synthetic Aperture Radar Antenna Onboard Airborne," Progress In Electromagnetics Research, vol. 163, pp. 107-117, 2018.

[18] M. F. E. Purnomo, S. Pramono, M. A. Pamungkas, and T. Taufik, "Study of the Effect of Air-Gap on Array Microstrip Antenna Performances for Mobile Satellite Communications," ARPN Journal of Engineering and Applied Sciences, vol. 10, no. 20, pp. 9808-9815, Nov. 2015.

[19] Y. K. Chan and V. C. Koo, "The Design and Development of Unmanned Aerial Vehicle Synthetic Aperture Radar," Progress In Electromagnetics Research Online, vol. 7, no. 7, pp. 685-688, 2011.

[20] V. C. Koo et al., "A New Unmanned Aerial Vehicle Synthetic Aperture Radar for Environmental Monitoring," Progress In Electromagnetics Research, vol. 122, pp. 245-268, 2012.

[21] A. Aguasca, R. A. Herrera, A. Broquetas, J. J. Mallorqui, and X. Fabregas, "ARBRES: Light-Weight CW/FM SAR Sensors for Small UAVs," Sensors, vol. 13, no. 3, pp. 3204-3216, 2013.

[22] M. F. E. Purnomo, V. Kusumasari, H. Suyono, and R. N. Hasanah, "The Four Patches of Triangular Microstrip Antennas as Configuration of CP-SAR," Proceedings of 2019 2nd International Conference on Electronics and Electrical Engineering Technology (EEET 2019), Penang Malaysia, Sep. 2019, pp. 55-61.

[23] M. F. E. Purnomo, V. Kusumasari, E. Supriana, R. Ambarwati, and A. Kitagawa, "Development of Triangular Array Eight Patches Antennas for Circularly-Polarized Synthetic Aperture Radar Sensor," TELKOMNIKA Telecommunication, Computing, Electronics and Control, vol. 18, no. 2, pp. 631-639, Apr. 2020, doi: 10.12928/TELKOMNIKA.v18i2.14759.

[24] M. F. E. Purnomo and A. Kitagawa, "Development of Equilateral Triangular Array Antenna with Truncated-Tip for Circularly Polarized-Synthetic Aperture Radar Sensor Application," Proceedings of 12th European Conference on Synthetic Aperture Radar, 2018. 
[25] M. F. E. Purnomo and A. Kitagawa, "Developing Basic Configuration of Triangle Array Antenna for Circularly Polarized-Synthetic Aperture Radar Sensor Application,” Proceedings of IEEE 2017 International Conference on Radar, Antenna, Microwave, Electronics, and Telecommunications (ICRAMET 2017), 2017, pp. 112-117.

[26] J. T. S. Sumantyo et al., "Development of Circularly Polarized Synthetic Aperture Radar on-board Microsatellite," PIERS Proceedings, 2009, pp. 382-385.

[27] Yohandri, V. Wissan, I. Firmansyah, P. R. Akbar, J. T. S. Sumantyo, and H. Kuze, "Development of Circularly Polarized Array Antenna for Synthetic Aperture Radar Sensor Installed on UAV," Progress In Electromagnetics Research C., vol. 19, pp. 119-133, 2011.

\section{BIOGRAPHIES OF AUTHORS}

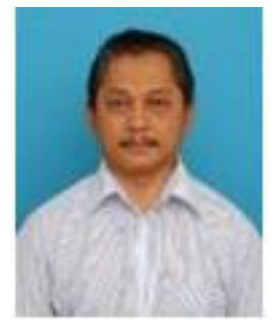

Muhammad Fauzan Edy Purnomo, was born in Banjarmasin, Indonesia, in June 1971. He received the Bachelor Engineering (B.E.) and Master Engineering (M.E.) degrees in Electrical Engineering from University of Indonesia, Jakarta, Indonesia in 1997 and 2000, respectively. He has graduated the doctoral degree in Electrical Engineering and Computer Science from Kanazawa University, Kanazawa, Japan on September 2018. He has finished a visiting scholar at Microelectronic Research Laboratory (MeRL), Division of Electrical Engineering and Computer Science, Graduate School of Natural Science and Technology, Kanazawa University, Japan on March 2019. From 2000 until present, he is working as lecturer at the Electrical Department Brawijaya University, Malang, Indonesia. His main interests are in the areas of microwave antennas, Radio Frequency (RF) circuit, wave signal processing, plasma wave engineering, array microstrip antennas, mobile cellular, satellite communications, wireless sensor network, internet of things, artificial intelligent, machine learning, remote sensing, Synthetic Aperture Radar (SAR), and Circularly-Polarized Synthetic Aperture Radar (CP-SAR).

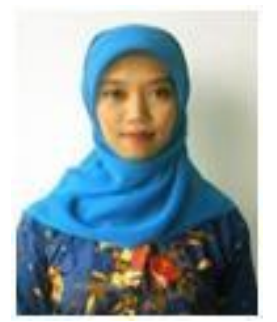

Vita Kusumasari, was born in 1983 in Malang, Indonesia. She obtained the bachelor degree in Mathematics in 2005 and the master degree in Mathematics Education in 2010 from Universitas Negeri Malang, Indonesia. She received the Ph.D degree in Mathematical and Physical Sciences in 2017 from Kanazawa University, Japan. Currently, she is a lecturer in Mathematics Department, Faculty of Mathematics and Natural Sciences, Universitas Negeri Malang. Her interests are numerical analysis and differential equations.

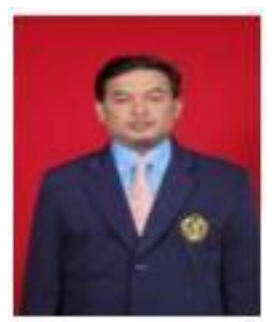

Rudy Yuwono was born in Blitar, june 15, 1971. He received bachelot degree from university of Brawijaya, Malang Indonesia in 1997 and master degree from University of Kassel, Germany in 2005 Curently, he is working at Electrical Engineering, University of Brawijaya Malang as Lecturer and Researcher. His research interest are antena and propagation, microwave and reasercher.

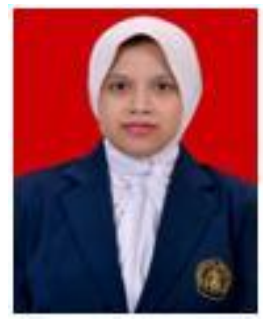

Rahmadwati, was born in Malang, Indonesia. She has received Bachelor Degree in Electrical Engineering from Brawijaya University in 2000. She received the Master Degree in Electrical Engineering from Gadjahmada University in 2004. And she received Doctoral Degree Electrical Engineering from University of Wollongong, Australia in2013. Her research interest include image processing, signal processing, machine learning and control system.

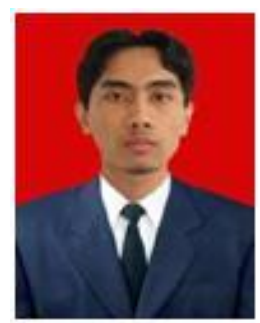

Rakhmad Romadhoni was born in Blitar, Indonesia, on May 1986. He received the S.ST (Sarjana Sain Terapan / Bachelor Applied Science) degree in Mechatronic Engineering from PENS-ITS, Surabaya in 201. He is working as Laboratory Technician at the Electrical Department Brawijaya University, Malang, Indonesia. 

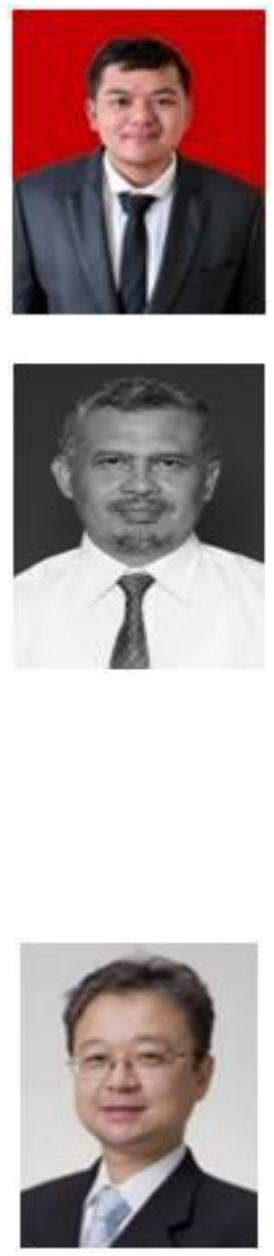

Azizurrahman Rafli was born in Malang, Indonesia on July 2000. He is 2018's Electrical Engineering student in Brawijaya University. He joined Aeronautics students research group as User Interface Programmer and he joined Transmission and Microwave laboratory as a research assistant. His main interest in Microstrip Antenna Design researches.

Yuyu Wahyu was born in Bandung, Indonesia, on February, 1962. He received the Ir. (Insinyur) degree in 1990, the M.Eng (M.T) degree in Telecommunication Information System from electrical engineering study program, in 2000, and the $\mathrm{PhD}$ degree in Global Information and Telecommunication Studies from school of electrical and informatics engineering, in 2010, all from Institut Teknologi Bandung, Bandung, Indonesia. He joined the Telecommunications Research Center, Strategic Electronics, Components and Materials (Telkoma) Indonesian Institute of Sciences (LIPI)-now the Research Center for Electronics and Telecommunications, LIPI, since 1991. He was chair of the research group of Antennas and Propagation from 2014 until now. Since 2019 he has been appointed as Research Professor in telecommunications transmission. He followed a number of activities related to his field of competence, i.e. active antenna and radar. He conducted FMCW radar research from 2006 to present and electronic support measure (ESM) from 2015 to 2018. He participated in professional organizations, including: Head of west java province for Himpenindo (Association of Indonesian Researchers) from 2020 to 2024. Indonesian Radar Association since 2008 until now, and IEEE - Antenna and Propagation Society since 2010 until now.

Akio Kitagawa, was born in Hikone, Japan in 1961. He received the B.E., the M.E., and the Ph.D degree from Nagoya Institute of Technology, Nagoya, Japan in 1985, 1987 and 1991, respectively. Since 1989, He worked for the Department of Electrical and Computer Engineering, Kanazawa University, Japan. From 2001 to 2003, He was with the Department of Information and Systems Engineering, Kanazawa University, Japan. From 2004 to 2007, He had been with Division of Electrical Engineering and Computer Science, Graduate School of Natural Science and Technology, Kanazawa University. Since 2008, He is working with College of Science and Engineering, School of Electrical, Information and Communication Engineering in Kanazawa University. His research interests include a phase change nonvolatile RAM, VLSI design automation, integrated sensor systems, RF circuit design and VLSI applications to mobile systems. 